\title{
The effect of temperature and pressure on the crystal structure of piperidine
}

\author{
Laura E Budd ${ }^{1}$, Richard M Ibberson ${ }^{2,3}$, William G Marshall ${ }^{2}$ and Simon Parsons ${ }^{1 *}$
}

\begin{abstract}
Background: The response of molecular crystal structures to changes in externally applied conditions such as temperature and pressure are the result of a complex balance between strong intramolecular bonding, medium strength intermolecular interactions such as hydrogen bonds, and weaker intermolecular van der Waals contacts. At high pressure the additional thermodynamic requirement to fill space efficiently becomes increasingly important.

Results: The crystal structure of piperidine- $\mathrm{d}_{11}$ has been determined at $2 \mathrm{~K}$ and at room temperature at pressures between 0.22 and $1.09 \mathrm{GPa}$. Unit cell dimensions have been determined between 2 and $255 \mathrm{~K}$, and at pressures up to $2.77 \mathrm{GPa}$ at room temperature. All measurements were made using neutron powder diffraction. The crystal structure features chains of molecules formed by $\mathrm{NH}$.... N H-bonds with van der Waals interactions between the chains. Although the $\mathrm{H}$-bonds are the strongest intermolecular contacts, the majority of the sublimation enthalpy may be ascribed to weaker but more numerous van der Waals interactions.

Conclusions: Analysis of the thermal expansion data in the light of phonon frequencies determined in periodic DFT calculations indicates that the expansion at very low temperature is governed by external lattice modes, but above $100 \mathrm{~K}$ the influence of intramolecular ring-flexing modes also becomes significant. The principal directions of thermal expansion are determined by the sensitivity of different van der Waals interactions to changes in distance. The principal values of the strain developed on application of pressure are similarly oriented to those determined in the variabletemperature study, but more isotropic because of the need to minimise volume by filling interstitial voids at elevated pressure.
\end{abstract}

\section{Background}

Piperazine and piperidine are heterocyclic molecules related to cyclohexane by substitution of one or two $\mathrm{CH}_{2}$ groups by $\mathrm{NH}$ (Scheme 1). Cyclohexane, the 'parent' compound in the series, exhibits a rich diversity of phases, having been studied under varying degrees of temperature and pressure. Two phases are accessible by varying temperature alone. Phase I (space group $F m \overline{3} m$ ), which occurs between the melting point $(279.82 \mathrm{~K})$ and $186.1 \mathrm{~K}$, is a plastic phase in which the molecules undergo rapid molecular re-orientations about the lattice points. At $186.1 \mathrm{~K}$ the structure converts to an ordered phase II (space group C2/c) [1]. This transition, which is thermodynamically first order, has recently been investigated

\footnotetext{
* Correspondence: s.parsons@ed.ac.uk

${ }^{1}$ EaStCHEM School of Chemistry and Centre for Science at Extreme Conditions, The University of Edinburgh, King's Buildings, West Mains Road, Edinburgh EH9 3FJ, UK

Full list of author information is available at the end of the article
}

using total neutron scattering techniques to reveal formation of domains resembling phase-II as the phase transition temperature is approached from above [2]. Though the structure of phase-II is ordered, the distribution of molecular centroids retains the cubic-close packed topology of the plastic form.

In cyclohexane-II the molecules are distributed in layers which stack in the $\mathrm{ABCABC} \ldots$ pattern characteristic of cubic close packing. In piperidine and piperazine the $\mathrm{NH}$ groups are capable of forming hydrogen bonds. In piperazine the arrangement of the molecular centroids is the same as in cyclohexane-II, but the molecules are rotated to enable H-bonds to form between the layers [3]. The structure of piperidine can also be considered to consist of layers, but the distribution of the molecules with respect to inversion centres in the space group makes the topology hexagonally close-packed. $\mathrm{H}$-bonds form only between alternate layers, and the structure can be considered to be a hybrid of cyclohexane 

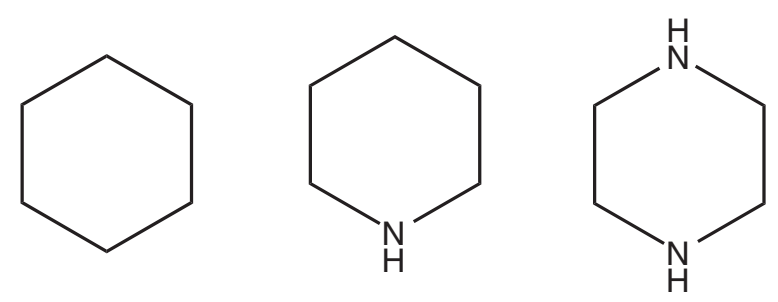

Scheme 1 Cyclohexane, piperidine and piperazine.

and piperazine. The rotations necessary for $\mathrm{H}$-bond formation optimise interactions between the NH groups, but at the expense of breaking the van der Waals interactions formed within the layers of cyclohexane, and piperidine has a somewhat lower packing coefficient [4] (0.66) than either cyclohexane or piperazine (0.71).

The low packing coefficient suggests that piperidine may be susceptible to formation of different phases. This suggestion is supported by differential scanning calorimetry data presented by Parkin [3], which show that piperidine appears to form one phase on cooling from the liquid, which then transforms to another phase at $239 \mathrm{~K}$. However, the higher temperature phase is not recovered on warming. In addition, during preliminary crystal growth experiments Parkin et al. obtained a weakly-diffracting form of piperidine with a cell volume approximately half of that of the phase they eventually characterised. The cell dimensions of this smaller-volume phase were $a=7.033$ (3), $b=5.224(3), c=7.852(4) \AA$ and $\beta=108.03(3)^{\circ}$. However, despite numerous attempts in which the cooling rate and sample size were varied this phase was never observed again.

The primary aim of the present investigation was therefore to determine if new forms of piperidine (in its perdeuterated form) could be identified under different conditions of temperature and pressure. The data collected also enable a detailed analysis of the thermodynamic properties of piperidine which are analysed with the aid of periodic DFT simulations and PIXEL packing energy calculations.

\section{Experimental}

Piperidine- $\mathrm{d}_{11}$ was obtained from Aldrich and used as received.

\section{Variable temperature measurements}

Variable temperature time-of-flight neutron powder diffraction data were recorded using the HRPD instrument at ISIS [5]. As piperidine is liquid under ambient conditions, piperidine- $\mathrm{d}_{11}$ was poured into a liquid nitrogen chilled stainless steel mortar [6] and cold-ground before being loaded into a rectangular aluminium sample can fitted with a heater. The sample was then placed in a cryostat held at $100 \mathrm{~K}$. After confirming the sample was in the known phase, the temperature was reduced to $2 \mathrm{~K}$ and data collected at this temperature. Data were then collected in $5 \mathrm{~K}$ steps from $5 \mathrm{~K}$ to $250 \mathrm{~K}$; there was no indication of a phase transition in this range. No evidence of a pre-melting transition was found on increasing the temperature further to $255 \mathrm{~K}$.

In order to investigate the possibility of a second phase close to the melting point, the sample was removed from the cryostat and allowed to melt. It was then transferred to a cylindrical vanadium can containing glass wool (to promote formation of a randomly-oriented powder) before being placed in a cryostat held at $245 \mathrm{~K}$. This should have been well above the transition temperature $(239 \mathrm{~K})$ reported in ref. [3], however upon crystallisation the known low temperature phase was obtained.

Quenching a similar sample of piperidine in liquid nitrogen also resulted in the sample crystallising into the same phase. No evidence for a second phase of piperidine was observed.

\section{High pressure measurements}

Ambient temperature, high pressure neutron powder diffraction data were collected using the time-of-flight technique on the PEARL beamline high pressure facility at ISIS $[7,8]$. Piperidine- $d_{11}$ was contained in a nullscattering Ti-Zr alloy capsule gasket [9] and loaded into a Paris-Edinburgh press [10-12]. The sample was loaded with powdered silica wool as previous work has shown it to aid formation of a well-oriented powder when crystallising liquids in situ; a small pellet of lead was included as a pressure marker. The pressure was calculated from the refined lead cell parameter using a Birch-Murnaghan equation of state $[13,14]$ with $V_{0}=30.3128 \AA^{3}, B=$ $41.92 \mathrm{GPa}, B^{\prime}=5.72$. These parameters were derived by Fortes $[15,16]$ by refitting data obtained in three earlier studies [17-19].

On increasing the pressure to $0.22 \mathrm{GPa}$ the sample crystallised in the monoclinic phase observed at low temperature. Diffraction data were collected at 0.22 , $0.49,0.80,1.09$ and $1.36 \mathrm{GPa}$ for $c a 700 \mu \mathrm{A} \mathrm{h}$, with shorter $(c a 100 \mu \mathrm{A} \mathrm{h})$ collections at 2.06 and $2.77 \mathrm{GPa}$. Peak broadening was pronounced above $1.09 \mathrm{GPa}$, because of the lack of a hydrostatic medium, and therefore the sample was decompressed to approximately 0.23 $\mathrm{GPa}$. Over a period of four hours the pressure decreased slightly resulting in the sample melting. Recompressing the sample to $0.30 \mathrm{GPa}$ resulted in the sample recrystallising in the same phase.

\section{Structure refinement}

Rietveld refinements [20] were performed using TOPASAcademic [21]. During refinement against the high-pressure data the piperidine molecules were treated as rigid groups using the Z-matrix formalism. Bond lengths and angles 
were taken from the previously determined structure (CSD refcode ITOBAU) [3] with deuterium distances set to standard neutron distances (N-H $1.009 \AA$, C-H $1.083 \AA$ ). Bond lengths, angles and torsion angles were not refined. All non-hydrogen atoms were refined with a common isotropic displacement parameter, as were all deuterium atoms. A fourth order spherical harmonic preferred orientation correction [22] was included as the sample was crystallised in situ. Ni and WC phases were also included in the refinement. The presence of these is due to the anvil cores of the Paris-Edinburgh press. Rietveld refinement profiles at 0.22 and $1.09 \mathrm{GPa}$ are shown in Figure 1a and b, with crystal and refinement data given in Table 1. Peak broadening was quite pronounced above 1.09 GPa and detailed structure analysis was not carried out above this pressure.

During refinement of the data collected at $2 \mathrm{~K}$ the piperidine molecules were treated using the $Z$-matrix formalism in TOPAS-Academic. Bond lengths and angles were refined, though all C-D distances were constrained to be equal. Anisotropic displacement parameters were modelled using the TLS formalism [23,24]. In spite of cold-grinding it was necessary to include a fourth order spherical harmonic correction for preferred orientation. The Rietveld refinement profile is shown in Figure 1c with crystal and refinement data given in Table 1. Pawley fits [25] were carried out on the rapid-scan data to obtain the lattice parameters.

\section{DFT calculations}

DFT calculations were performed on piperidine- $d_{11}$ using the plane-wave pseudopotential method in the CASTEP code [26] as incorporated into Materials Studio version 7 [27]. The PBE exchange-correlation functional [28] was used with norm-conserving pseudopotentials and a basis set cut-off energy of $950 \mathrm{eV}$. Brillouin zone integrations
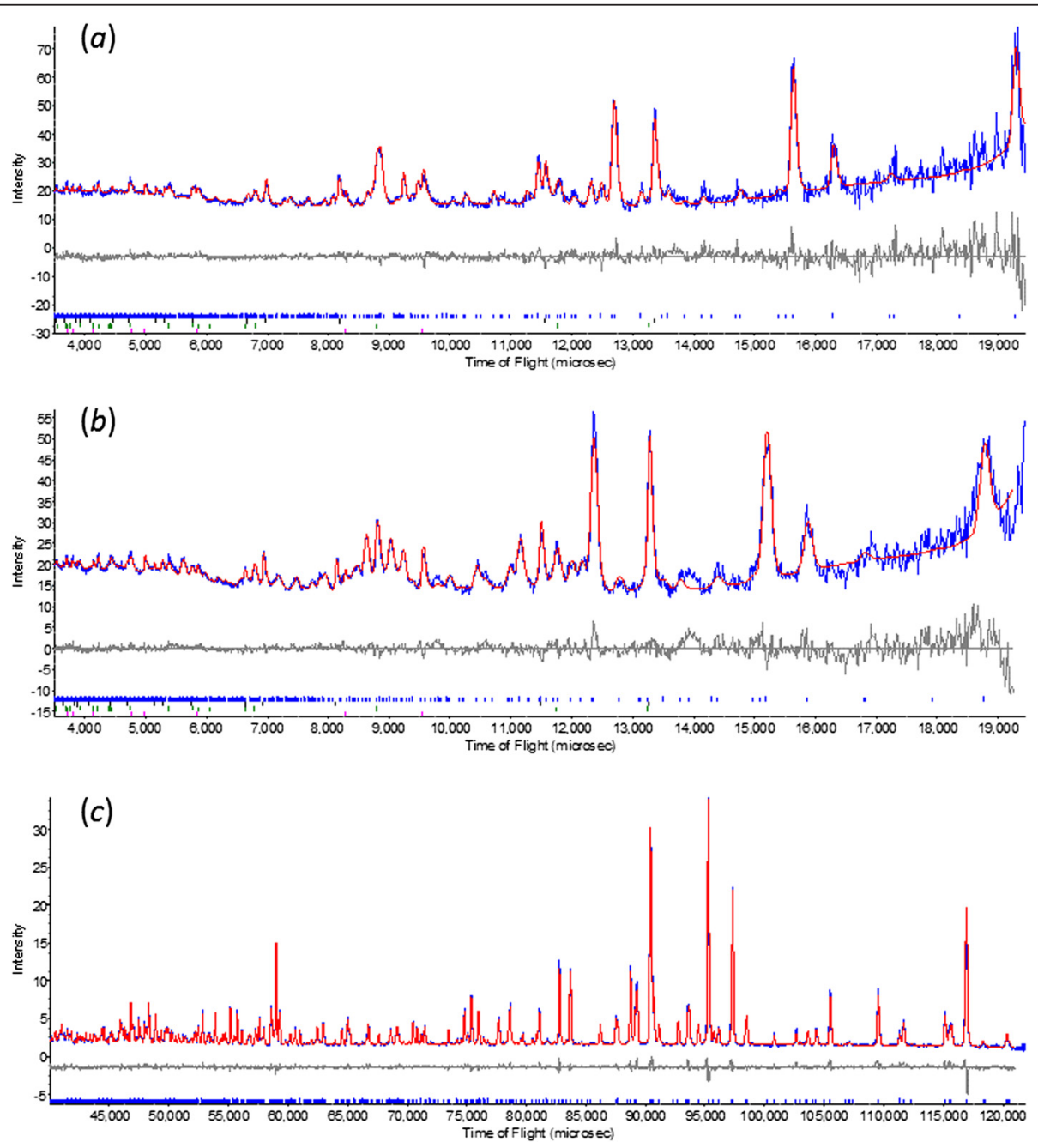

Figure 1 Rietveld refinement fits at (a) $0.22 \mathrm{GPa}$ and room temperature, (b) $1.09 \mathrm{GPa}$ and room temperature and (c) $2 \mathrm{~K}$ and ambient pressure. The $d$-spacing ranges are $0.73-4.16 \AA$ for $(\boldsymbol{a})$ and $(\boldsymbol{b})$ and $0.83-2.75 \AA$ for $(\boldsymbol{c})$. 
Table 1 Crystal and refinement data

\begin{tabular}{|c|c|c|c|c|c|}
\hline Pressure (GPa) & 0.22 & 0.49 & 0.80 & 1.09 & Ambient \\
\hline Temperature (K) & 298 & 298 & 298 & 298 & 2 \\
\hline Chemical formula & $\mathrm{C}_{5} \mathrm{D}_{11} \mathrm{~N}$ & $\mathrm{C}_{5} \mathrm{D}_{11} \mathrm{~N}$ & $\mathrm{C}_{5} \mathrm{D}_{11} \mathrm{~N}$ & $\mathrm{C}_{5} \mathrm{D}_{11} \mathrm{~N}$ & $\mathrm{C}_{5} \mathrm{D}_{11} \mathrm{~N}$ \\
\hline$M_{r}$ & 96.17 & 96.17 & 96.17 & 96.17 & 96.17 \\
\hline Cell setting, space group & Monoclinic, $P 2_{1} / c$ & Monoclinic, $P 2_{1} / C$ & Monoclinic, $P 2{ }_{1} / C$ & Monoclinic, $P 2_{1} / C$ & Monoclinic, $P 2_{1} / C$ \\
\hline$a, b, c(\AA)$ & $\begin{array}{l}8.6994(17), 5.2552(9) \\
11.9045(16)\end{array}$ & $\begin{array}{l}8.5969(12), 5.2010(7) \\
11.7936(12)\end{array}$ & $\begin{array}{l}8.5150(14), 5.1577(8), \\
11.6988(14)\end{array}$ & $\begin{array}{l}8.4452(15), 5.1204(9) \\
11.6181(16)\end{array}$ & $\begin{array}{l}8.59695(4), 5.21506(2) \\
11.93271(4)\end{array}$ \\
\hline$a, \beta, \gamma\left({ }^{\circ}\right)$ & $90,96.468(17), 90$ & $90,96.507(14), 90$ & 90, 96.532(15), 90 & 90, 96.558(17), 90 & $90,96.8790(4), 90$ \\
\hline$V\left(\AA^{3}\right)$ & $540.77(16)$ & $523.93(12)$ & $510.45(13)$ & $499.11(14)$ & $531.135(4)$ \\
\hline Z & 4 & 4 & 4 & 4 & 4 \\
\hline$D_{\text {calc }}\left(\mathrm{g} \mathrm{cm}^{-3}\right)$ & 1.181 & 1.219 & 1.251 & 1.280 & 1.203 \\
\hline Diffractometer & PEARL, ISIS & & & & HRPD, ISIS \\
\hline Collection method & Time of flight & Time of flight & Time of flight & Time of flight & Time of flight \\
\hline Fitted range of d $(\AA)$ & $0.75-4.17$ & $0.75-4.17$ & $0.75-4.17$ & $0.75-4.12$ & $0.83-2.51$ \\
\hline$R_{p}(\%)$ & 5.329 & 4.484 & 4.370 & 4.363 & 4.626 \\
\hline$R_{w p}(\%)$ & 4.226 & 3.485 & 3.265 & 3.396 & 5.589 \\
\hline S & 1.294 & 1.432 & 1.344 & 1.395 & 1.544 \\
\hline Background & \multicolumn{4}{|l|}{$\begin{array}{l}9 \text { term } \\
\text { Chebychev polynomial }\end{array}$} & $\begin{array}{l}6 \text { term } \\
\text { Chebychev polynomial }\end{array}$ \\
\hline Profile function & \multicolumn{5}{|c|}{ Back-to-back exponential convoluted with Voigt function } \\
\hline Number of parameters & 42 & 42 & 42 & 42 & 74 \\
\hline
\end{tabular}

were performed with a Monkhorst-Pack [29] k-point grid spacing of $0.07 \AA^{-1}$, corresponding to a grid of $2 \times 3 \times 1$ points. These parameters gave an energy convergence of $<0.1 \mathrm{meV} /$ atom.

For analysis of the effect of pressure and temperature on intermolecular interactions geometry optimisations were carried out while holding the unit cell parameters fixed to those observed experimentally. The total energy convergence tolerance was $5 \times 10^{-6} \mathrm{eV} /$ atom, with a maximum force tolerance of $0.01 \mathrm{eV} \AA^{-1}$ and a maximum displacement of $5 \times 10^{-4} \AA$. The SCF convergence criterion was $5 \times 10^{-7} \mathrm{eV} /$ atom, and the space group symmetry was retained during geometry optimisation.

For frequency calculations, the geometry optimisation was carried out in two stages. The coordinates and unit cell dimensions were optimised using the TkatchenkoScheffler correction for dispersion (DFT-D) [30,31] starting from the experimentally determined structure determined at $2 \mathrm{~K}$. The convergence criteria at this stage were the same as those given above with the additional requirement of a maximum stress tolerance of $0.02 \mathrm{GPa}$. The optimised cell parameters and volume were: $a=8.537417$ [expt at 2 K: 8.59695(4)] $\AA, b=5.169532$ [5.21506(2)] $\AA$,

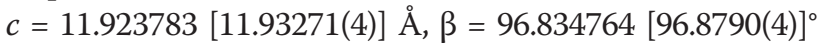
and $V=522.509783$ [531.14(1)] $\AA^{3}$, reproducing the cell dimensions to within $1 \%$ and the volume to $1.6 \%$. Linear response [32] calculations are not yet possible in CASTEP with dispersion-corrected functionals, and so a second stage of optimisation was carried out with the pure PBE functional holding the cell dimensions fixed. At this stage the energy convergence tolerance was $5 \times 10^{-7} \mathrm{eV} /$ atom, with a maximum force tolerance of $0.002 \mathrm{eV} \AA^{-1}$ and a maximum displacement of $5 \times 10^{-5} \AA$; the SCF convergence criterion was $5 \times 10^{-10} \mathrm{eV} /$ atom. The maximum force on any atom at convergence was $0.00012 \mathrm{eV} \AA^{-1}$. Phonon density-of-states and dispersion curves were calculated with Fourier interpolation [33]. No imaginary frequencies were observed at any point in the Brillouin zone. Generation of structures distorted along phonon modes was accomplished with MODE_FOLLOW [34].

\section{PIXEL calculations}

Electron densities were calculated using Gaussian09 [35] at the MP2 level of theory with the $6-31 G^{* *}$ basis set using molecular geometries derived from the crystal structures. The PIXEL method [36-40], as implemented in the program OPiX [41], was then used to calculate the intermolecular interaction energies.

\section{Other programs used}

Structures were visualised with XP [42], MERCURY [43] and DIAMOND [44]. Strain tensor calculations were carried out using a locally written program [45], based on the discussion by Ohashi and Burnham [46,47] and employing the JACOBI subroutine Numerical Recipes [48]. Equation-of-state calculations were performed using 
EOSfit [49]. ORIGIN was used for fitting of the unit cell parameters to variable temperature unit cell data. Animated GIFs were created from images generated in MERCURY using the web-site http://www.gifmaker.me/\#003.

\section{Results and discussion}

The crystal structure of piperidine has been previously determined from X-ray data at $150 \mathrm{~K}$. Variable temperature neutron powder diffraction revealed the structure exists between $2 \mathrm{~K}$ and $255 \mathrm{~K}$. Attempts to access another phase by crystallisations via rapid cooling to $245 \mathrm{~K}$ and $77 \mathrm{~K}$ were not successful. Crystallisation via the application of pressure resulted in the same phase as obtained at low temperature. No phase transitions were evident upon compression to $2.77 \mathrm{GPa}$.

\section{The crystal structure of piperidine}

Piperidine crystallises in the monoclinic space group $P 2_{1} / c$ with one molecule in the asymmetric unit (Figure 2) occupying a general position. Bond distances and angles adopt normal values as compared against similar structures in the Cambridge Database [50]. Ring-puckering analysis indicates that the molecule adopts an ideal chair conformation [51]. The hydrogen atom is attached to the nitrogen in the equatorial ring position.

PIXEL calculations yield a value of $57 \mathrm{kJmol}^{-1}$ for the sublimation enthalpy. The sublimation enthalpy at $262.12 \mathrm{~K}$ estimated from the experimentally-determined enthalpies of fusion [52] and vaporisation [53] and the heat capacities $\left(C_{\mathrm{p}}\right)$ of the liquid [52] and gas [53] is also $57 \mathrm{~kJ} \mathrm{~mol}^{-1}$, in excellent agreement with the PIXEL value. For comparison,

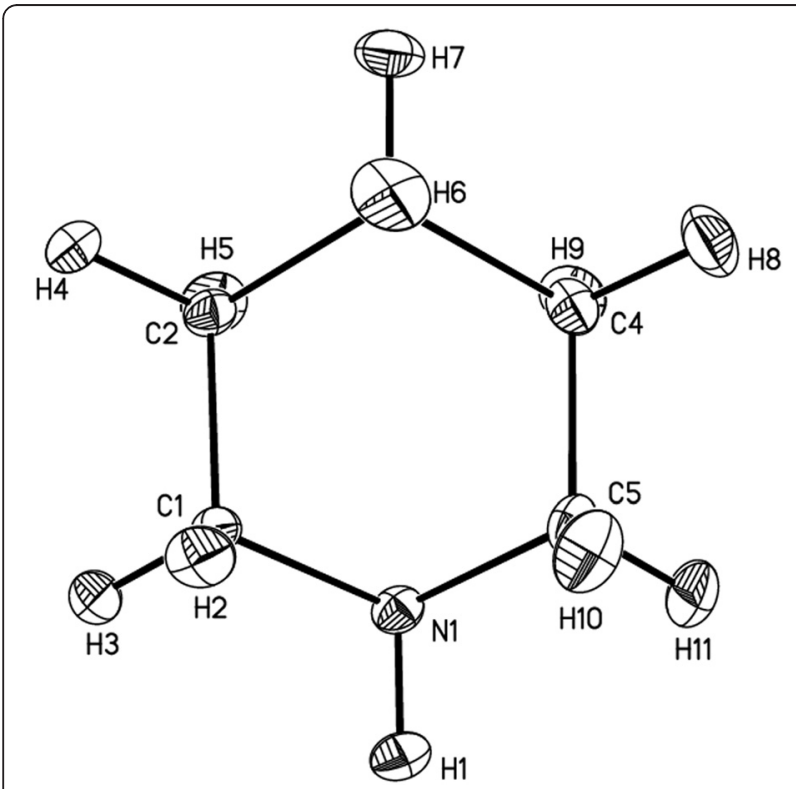

Figure 2 The molecular structure of piperidine at $2 \mathrm{~K}$ showing the displacement ellipsoids at the 50\% probability level. cyclohexane and piperazine have sublimation enthalpies of 37 and $72 \mathrm{kJmol}^{-1}$, respectively [54]. The most significant intermolecular interaction is an $\mathrm{N}-\mathrm{H}$... $\mathrm{N}$ hydrogen bond [2.141(3) $\AA$ at $2 \mathrm{~K}$ ] which links the molecules to form chains parallel to $\mathbf{b}$, Figure $3 \mathrm{a}$ and Table 2. Successive molecules along the chains are related by the $2_{1}$ screw axis. The PIXEL calculations indicate that the H-bond energy is $23 \mathrm{~kJ} \mathrm{~mol}^{-1}$, accounting for about $40 \%$ of the calculated sublimation enthalpy. Ten more intermolecular contacts are formed with energies of between 8 and $4 \mathrm{~kJ}$ $\mathrm{mol}^{-1}$, with dispersion being the largest contributing term in each case (Table 2). Each of these contacts features a $\mathrm{H}$...H contact distance of between 2.36 and $2.59 \AA$, i.e. at or slightly more than twice the sum of the of the van der Waals radius of $H(2.4 \AA)$. The contacts with energies of 8 $\mathrm{kJmol}^{-1}$ are formed to the next-nearest-neighbours within the $\mathrm{H}$-bonded chains. The $\mathrm{H}$-bonded chains are arranged so that the molecules of one chain fit into the grooves of the neighbouring chains (Figure $3 \mathrm{~b}$ ), and overall the twelve contacts are distributed with molecular centroids in the approximately close-packed arrangement identified in the original report of the structure. In Figure $3 \mathrm{~b}$ the layers alluded to in Introduction run horizontally. The largest contact energy beyond the set of 12 contacts just described is $1.6 \mathrm{~kJ} \mathrm{~mol}^{-1}$.

Anisotropic displacement parameters were modelled using TLS rigid-body constraints [23,24]. The two largest principal axes of the libration tensor, shown in Figure 4a are located in the mean plane of the molecule with magnitudes of approximately 19 degrees $^{2}$, with the third, out-of-plane, axis having a magnitude of 4.2 degrees $^{2}$. These data indicate that at $2 \mathrm{~K}$ the molecular motion consists mainly of in-plane rocking vibrations. This description of the molecular motion is broadly reproduced in the displacement parameters calculated from the periodic DFT phonon calculations (Figure 4b). The two in-plane $L$ tensor eigenvalues have magnitudes of 12.0 and 15.0 degrees $^{2}$, with the third axis having a value of 5.8 degrees $^{2}$. The corresponding in-plane eigenvectors, though similar, are rotated by $29.6^{\circ}$ relative to the experimental values. Considering the approximations made in the calculations (e.g. harmonicity), the nearly isotropic cross-section of the $L$ tensor, the tendency for displacement parameters to 'mop-up' experimental errors such as absorption and the fact that the atomic motions are independent and not part of a rigid body in the DFT calculation, the overall the agreement between the experimental and theoretical results is quite satisfactory.

The effect of temperature on the structure of piperidine The low temperature behaviour of piperidine was surveyed from $5 \mathrm{~K}$ to $255 \mathrm{~K}$ with data collected every $5 \mathrm{~K}$. The extracted lattice parameters are given in the Additional file 1: Table S1 and displayed in Figure 5. The data exhibit 


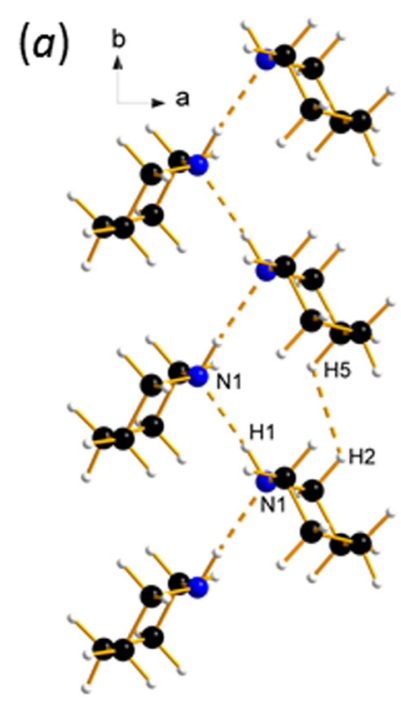

(c)

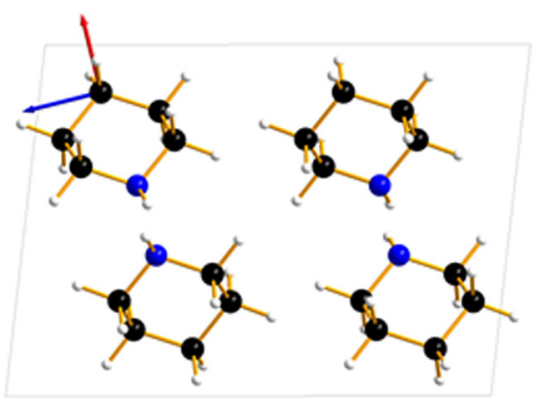

(b)

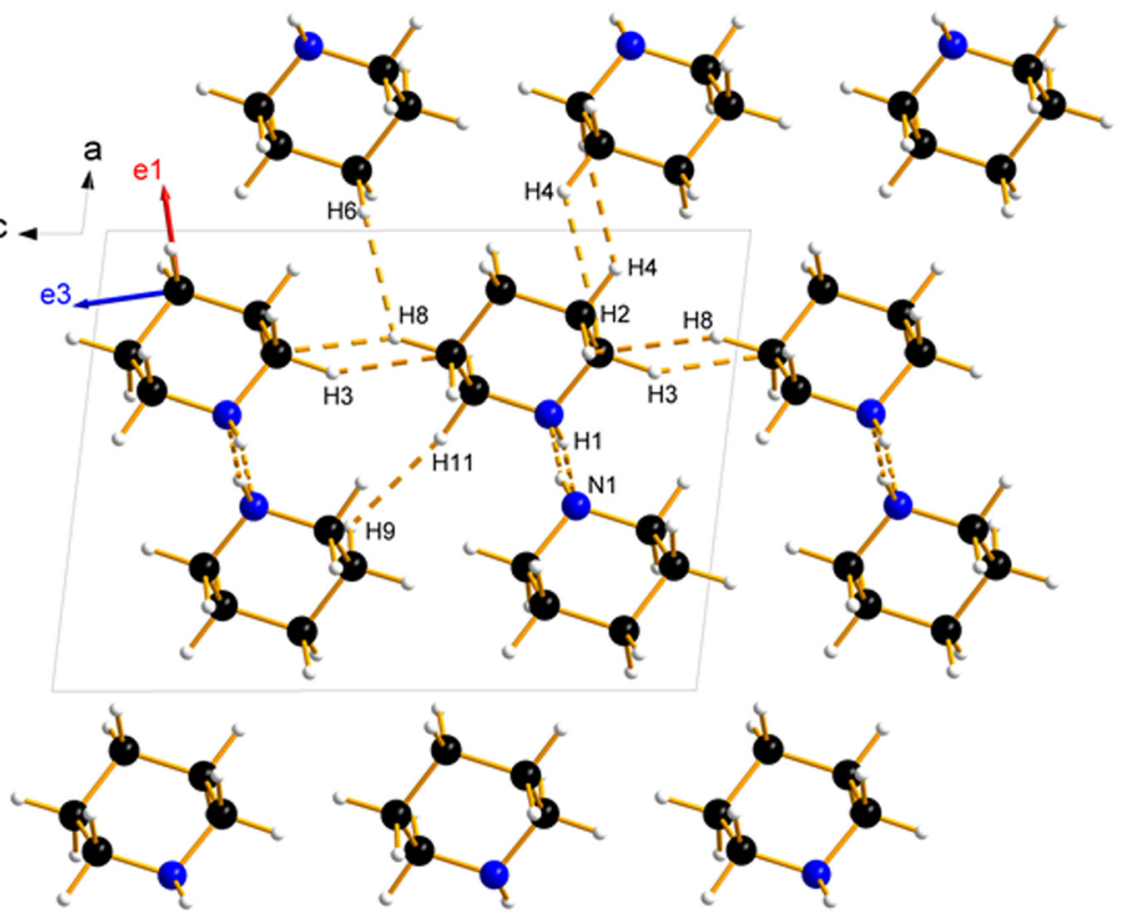

Figure 3 Intermolecular interactions in piperidine. (a) H-bonded chain at $2 \mathrm{~K}$ viewed along c. (b) View along $\mathbf{b}$ at $2 \mathrm{~K}$. (c) View along $\mathbf{b}$ at 0.22 $\mathrm{GPa}$. In $(\boldsymbol{a})$ and $(\boldsymbol{b}) \mathrm{H}$...H contacts listed in Table 2 are also shown. In $(\boldsymbol{b})$ and $(\boldsymbol{c})$ the directions of the maximum and minimum eigenvalues of the strain tensor are shown in red and blue, respectively.

a smooth expansion of the unit cell with no evidence of a phase transition.

The unit cell volume versus temperature data (Figure 5e) can be analysed following the methods described in refs [55-57]. This analysis starts with the definition of the Grüneisen ratio, $\gamma[58,59]$,

$$
\gamma=\frac{\alpha V B}{C_{v}}
$$

where $\alpha$ is the volume thermal expansion coefficient, $B$ the isothermal bulk modulus, $V$ is the unit cell volume and $C_{\mathrm{v}}$ the constant-volume heat capacity. Assuming both $\gamma$ and $B$ are independent of temperature, integration of [1] with respect to temperature gives

$$
\frac{\gamma}{B}\left[U(T)-U\left(T_{0}\right)\right]=V(T)-V\left(T_{0}\right)
$$


Table 2 Intermolecular contact distances in piperidine- $d_{11}$ as determined by neutron powder diffraction, and moleculemolecule contact energies $E$ estimated in PIXEL calculations

\begin{tabular}{|c|c|c|c|c|c|c|c|c|c|}
\hline Contact & Symmetry operation & $\begin{array}{l}-E_{\text {coul }} \\
\mathrm{kJmol}^{-1}\end{array}$ & $\begin{array}{l}-E_{\mathrm{POL}} / \\
\mathrm{kJmol}^{-1}\end{array}$ & $\begin{array}{l}-E_{\mathrm{DISP}} / \\
\mathrm{kJmol}^{-1}\end{array}$ & $\begin{array}{l}E_{\mathrm{REP}} / \\
\mathrm{kJmol}^{-1}\end{array}$ & $\begin{array}{l}-E_{\mathrm{TOT}} / \\
\mathrm{kJmol}^{-1}\end{array}$ & Distance/Å & Distance/Å & Distance/Å \\
\hline$T$ or $P$ & & & & & & & $T=2 \mathrm{~K}$ & $P=0.22 \mathrm{GPa}$ & $P=1.09 \mathrm{GPa}$ \\
\hline \multicolumn{10}{|c|}{ Contacts formed within $\mathrm{H}$-bonded chains } \\
\hline 1. N1 ...H1-N1 & {$[-x+1, y-1 / 2,-z+1 / 2]$} & 30.5 & 11.8 & 19.2 & 38.9 & 22.7 & $2.141(3)$ & 2.18 & 2.09 \\
\hline 2. $\mathrm{N} 1-\mathrm{H} 1 \ldots \mathrm{N} 1$ & {$[-x+1, y+1 / 2,-z+1 / 2]$} & 30.5 & 11.8 & 19.2 & 39 & 22.6 & $2.141(3)$ & 2.18 & 2.09 \\
\hline 3. $\mathrm{C} 1-\mathrm{H} 2 \ldots \mathrm{H} 5$ & {$[x, y+1, z]$} & 4.2 & 1.9 & 15.5 & 13.4 & 8.2 & $2.365(6)$ & 2.41 & 2.27 \\
\hline 4. $\mathrm{C} 2-\mathrm{H} 5 \ldots \mathrm{H} 2$ & {$[x, y-1, z]$} & 4.2 & 1.9 & 15.5 & 13.4 & 8.2 & $2.365(6)$ & 2.41 & 2.27 \\
\hline \multicolumn{10}{|c|}{ Contacts formed between $\mathrm{H}$-bonded chains } \\
\hline 5. $\mathrm{C} 2-\mathrm{H} 4 \ldots \mathrm{H} 2$ & {$[-x+2, y-1 / 2,-z+1 / 2]$} & 2.2 & 1.2 & 12.1 & 9.5 & 6.0 & $2.373(9)$ & 2.42 & 2.31 \\
\hline 6. $\mathrm{C} 1-\mathrm{H} 2 \ldots \mathrm{H} 4$ & {$[-x+2, y+1 / 2,-z+1 / 2]$} & 2.2 & 1.2 & 12.1 & 9.5 & 6.0 & $2.373(9)$ & 2.42 & 2.31 \\
\hline 7. $\mathrm{C} 4-\mathrm{H} 8 \ldots \mathrm{H} 6$ & {$[-x+2,-y,-z+1]$} & 2.4 & 1.0 & 11.2 & 8.8 & 5.7 & $2.446(14)$ & 2.49 & 2.38 \\
\hline 8. $\mathrm{C} 5-\mathrm{H} 11 \ldots \mathrm{H} 9$ & {$[-x+1,-y,-z+1]$} & 3.0 & 1.5 & 10.5 & 9.7 & 5.4 & $2.382(13)$ & 2.44 & 2.26 \\
\hline 9. $\mathrm{C} 5-\mathrm{H} 10 \ldots \mathrm{H} 3$ & {$[x,-y+1 / 2, z+1 / 2]$} & 1.1 & 0.4 & 6.8 & 3.9 & 4.4 & $2.588(9)$ & 3.04 & 2.51 \\
\hline 10. C1-H3...H10 & {$[x,-y+1 / 2, z-1 / 2]$} & 1.1 & 0.4 & 6.8 & 3.9 & 4.4 & $2.588(9)$ & 3.04 & 2.51 \\
\hline 11. C4-H8...H5 & {$[x,-y-1 / 2, z+1 / 2]$} & 1.7 & 0.7 & 8.0 & 6.3 & 4.1 & $2.443(6)$ & 2.51 & 2.33 \\
\hline 12. $\mathrm{C} 2-\mathrm{H} 5 \ldots \mathrm{H} 8$ & {$[x,-y-1 / 2, z-1 / 2]$} & 1.7 & 0.7 & 8.0 & 6.3 & 4.1 & $2.443(6)$ & 2.51 & 2.33 \\
\hline
\end{tabular}

The subscripts COUL, POL, DISP, REP and TOT refer to Coulombic, polarisation, dispersion, repulsion and total energy terms. Distances from the high-pressure measurements are quoted without uncertainties because the piperidine molecules were treated as rigid bodies during refinement.

where $T_{0}$ is a reference temperature and $U$ refers to internal energy. Equation 2 demonstrates that the unit cell volume is a probe for changes in internal energy as a function of temperature.

The internal energy can be estimated using the Einstein model, Equ. 3, which assumes that all $N$ atoms in the unit cell vibrate at the same frequency, $v$, and the Einstein temperature $\theta=h v / k$, where $h$ is Planck's constant.

$$
U(T)=3 N k \theta\left(\frac{1}{2}+\frac{1}{\exp (\theta / T)-1}\right)
$$

Substitution of [3] into [2] gives

$$
\frac{3 N k \theta \gamma}{B}\left(\frac{1}{\exp (\theta / T)-1}-\frac{1}{\exp \left(\theta / T_{0}\right)-1}\right)=V(T)-V\left(T_{0}\right)
$$

As $T_{0}$ approaches zero the term $1 / \exp \left(\theta / T_{0}\right)-1$ becomes small enough to be neglected, and

$$
V(T)=V\left(T_{0}\right)+X\left(\frac{1}{\exp (\theta / T)-1}\right)
$$

where

$$
X=\frac{3 N k \theta \gamma}{B}
$$

Fitting of volume versus temperature data using equation (5) yields values of $\theta, V\left(T_{0}\right)$ and $X$ which can be interpreted in terms of vibrational, structural and heat capacity data.

Equation (5) was found to be inadequate for fitting the unit cell volume versus temperature data. Fitting to a 'double-Einstein' expression of the form

$$
V(T)=V\left(T_{0}\right)+X_{1}\left(\frac{1}{\exp \left(\theta_{1} / T\right)-1}\right)+X_{2}\left(\frac{1}{\exp \left(\theta_{2} / T\right)-1}\right)
$$

was more successful (Figure 5e), yielding Einstein temperatures of 101.6(14) and 773(18) K (Table 3), which correspond to vibrational energies of $c a 70$ and $540 \mathrm{~cm}^{-1}$. The relatively large uncertainty on $\theta_{2}$ is a reflection of its value being well beyond the temperature range used for its determination. It was also possible to fit the unit cell lengths in the same way, and the results are depicted in Figure 5a-c, with parameters listed in Table 3. The angle $\beta$ varies by little more than $0.3^{\circ}$ (Figure $5 \mathrm{~d}$ ) over the temperature range studied, increasing very slightly between 2 and $50 \mathrm{~K}$ and decreasing thereafter. Einstein functions fail to model this trend, and for the purposes of interpolation the values were fitted to a quartic polynomial.

The Einstein temperatures extracted from the volume versus temperature data are in reasonable agreement with values determined from heat capacities $\left(C_{\mathrm{v}}\right)$ simulated as a function of temperature using the results of the DFT phonon calculations (121 and $801 \mathrm{~K}$ ). The phonon density of states plot shown in Figure 6 suggests 


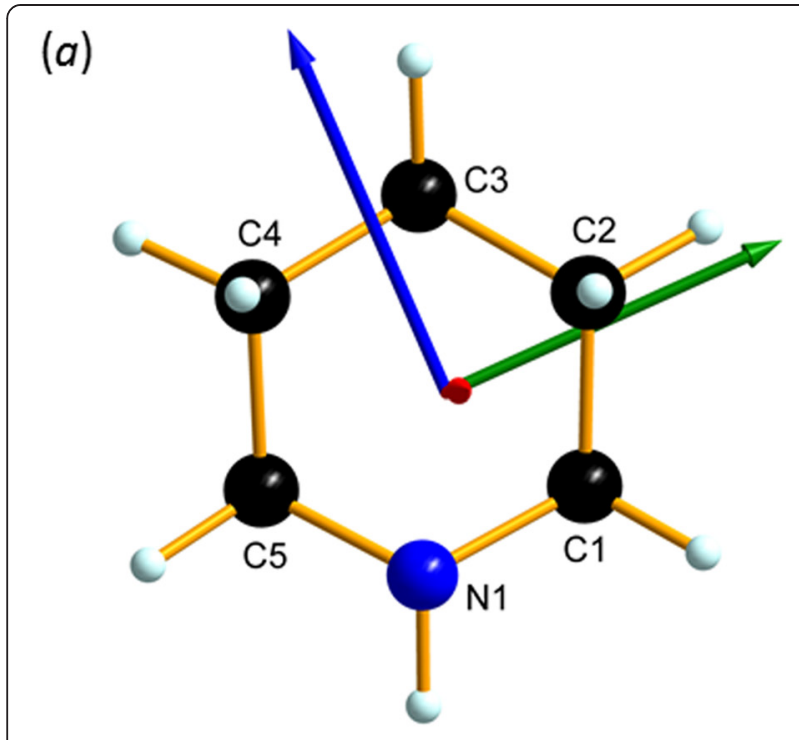

(b)

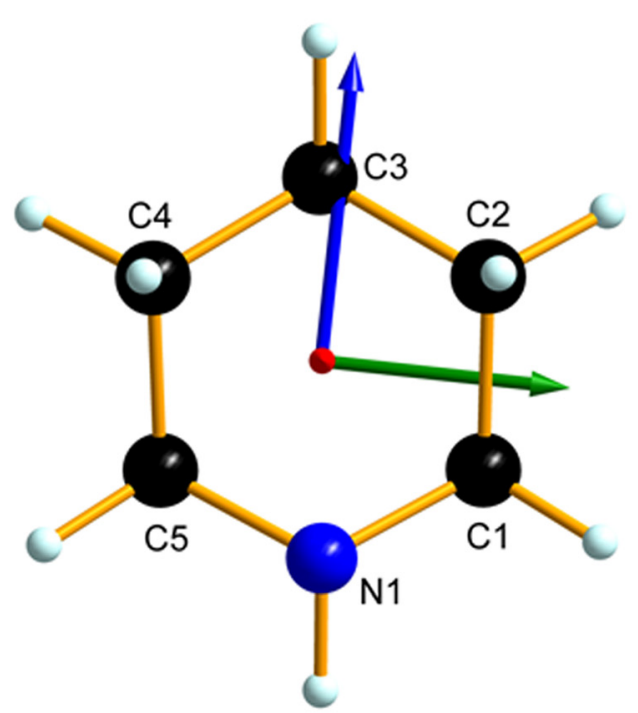

Figure 4 Largest eigenvalues of the rigid body thermal motion libration tensor $L$, determined (a) from experimental data at $2 \mathrm{~K}$ and (b) from a periodic DFT phonon calculation.

that the single-frequency model was unsuccessful because the low-frequency phonon region divides into one block at about $100 \mathrm{~cm}^{-1}$ composed of intermolecular modes, and a second from $200-500 \mathrm{~cm}^{-1}$ corresponding to intramolecular torsional modes such as ring-flexing. Both sets of vibrations contribute to the internal energy between 2 and $255 \mathrm{~K}$, and both therefore need to be taken into account in the data-fitting model.

The thermal expansion tensor was obtained by dividing the strain tensor evaluated for pairs of neighbouring temperature points by the temperature increment. This procedure yields identical diagonal strain tensor elements as given by Schlenker et al. [60] The off-diagonal term is approximately equal to Schlenker et al.'s formula for small changes in $\beta$. The tensors so-obtained were diagonalised using the JACOBI routine from Numerical Recipes [48]. The data are shown in Figure 7a, with the trend-line obtained in the same way using ideal values of the cell dimensions from the double-Einstein fitting described above. The largest component $[\alpha(1)]$ is approximately aligned with $\mathbf{a}^{*}$, the mean angle being $8^{\circ}$ between 32 and $225 \mathrm{~K} . \alpha(3)$, the smallest component is approximately aligned along $\mathbf{c}^{*}$. One axis, in this case $\alpha(2)$, must lie along $\mathbf{b}$ by symmetry. Though $\alpha(3)$ tends towards a constant value at $255 \mathrm{~K}$, all three curves have positive slopes at the melting point, suggesting that new vibrational energy levels are being accessed throughout the temperature range studied. At $255 \mathrm{~K}$ the expansion coefficients measured from the trend-lines are 17.3(3), 12.1(2) and 5.5(3) $\times 10^{-5}$ $\mathrm{K}^{-1}$ for $\alpha(1)-\alpha(3)$, respectively. The increase in unit cell volume between $2 \mathrm{~K}$ and $255 \mathrm{~K}$ is $31.16 \AA^{3}$ which represents $5.9 \%$ of the volume at $2 \mathrm{~K}$; the variation of the volume expansion coefficient is shown in Figure 7b.

Structures of piperidine were optimised by periodic DFT using cell dimensions fixed to the experimentallydetermined values at $2 \mathrm{~K}$ and in $25 \mathrm{~K}$ steps from $25 \mathrm{~K}$ to $250 \mathrm{~K}$. The resulting structures were then combined into a movie, available in the Additional file 2: Movie S1, enabling the thermal expansion to be visualised. The $\mathrm{H}$-bonded chains are arranged in rows which run parallel to c; these rows move apart as temperature is increased. Interestingly, the largest expansion component is the one approximately aligned with the axis $(a)$ associated with the largest Einstein temperatures given in Table 3; similarly the smallest component lies approximately along $c$, which is associated with the smallest Einstein temperatures. In part, this may be the result of applying Equ. 5 to cell dimension data, when it strictly applies only to volume. However, the strain tensors components obtained from the variable temperature and pressure experiments adopt a similar alignment, suggesting that the anisotropy of thermal expansion is determined by the compressibility of the structure along different directions (see below).

The constant-pressure heat capacity $\left(C_{\mathrm{p}}\right)$ of crystalline piperidine- $\mathrm{h}_{11}$, which has been measured as a function of temperature [52], can be converted to the constantvolume heat capacity $\left(C_{\mathrm{v}}\right)$ using Equ. $7[58,59]$ :

$$
C_{\mathrm{v}}=C_{\mathrm{p}}-\alpha^{2} T V B
$$

The values of $C_{\mathrm{v}}$ determined in this way agree well with those derived from the phonon density of states calculated by periodic DFT on $\mathrm{C}_{5} \mathrm{H}_{11} \mathrm{~N}$ (Figure 8a). Values of $C_{\mathrm{v}}$ were therefore calculated in the same way for $C_{5} D_{11} N$. The results are also shown in Figure 8a, the generally increased values being the result of the smaller 
(a)

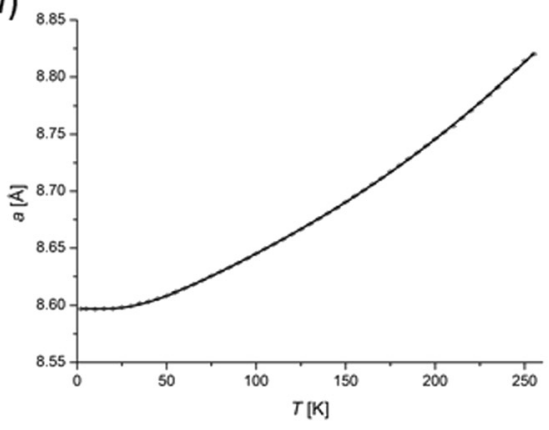

(b)

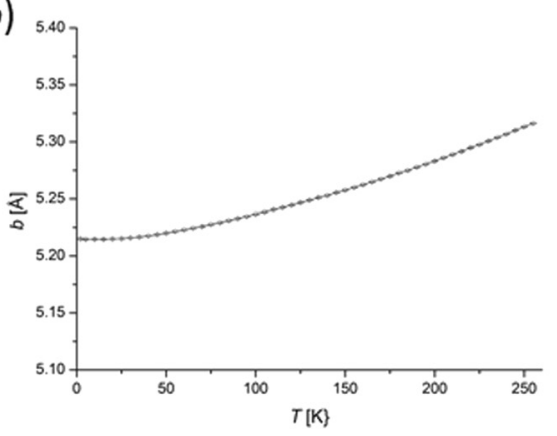

(c)

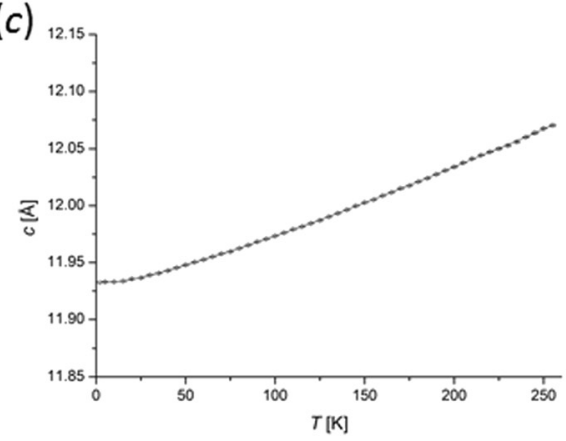

(d)

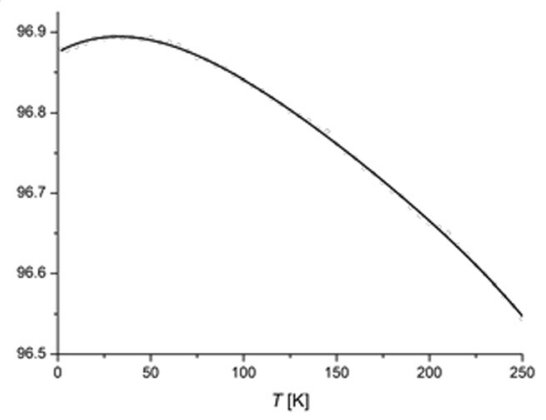

(e)

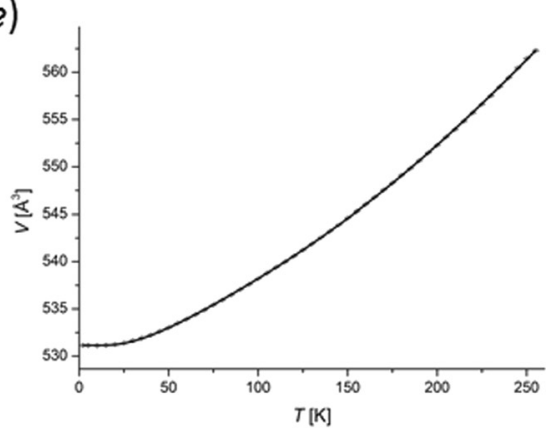

Figure 5 Variation of the unit cell dimensions with temperature. (a) the $a$-axis length, (b) the $b$-axis length, (c) the $c$-axis length, (d) the $\beta$ angle and $(\boldsymbol{e})$ the volume. The vertical axes in plots $a-c$ span the same distance range.

vibrational frequencies for the deuterated isotopologue. The calculated heat capacities were combined with data for the variation of $V$ and the thermal expansion coefficient with temperature, and the bulk modulus determined from the high-pressure measurements described below, to obtain the temperature dependence of the

Table 3 Einstein model fitting parameters

\begin{tabular}{llllll}
\hline & $\boldsymbol{X}_{\mathbf{0}} / \AA ̊$ or $\AA^{\mathbf{3}}$ & $\boldsymbol{X}_{\mathbf{1}} / \AA$ or $\AA^{\mathbf{3}}$ & $\boldsymbol{X}_{\mathbf{2}} / \AA$ or $\AA^{\mathbf{3}}$ & $\boldsymbol{\Theta}_{\mathbf{1}} / \mathbf{K}$ & $\boldsymbol{\Theta}_{\mathbf{2}} / \mathbf{K}$ \\
\hline$V$ & $531.142(13)$ & $12.4(3)$ & $116(7)$ & $101.6(14)$ & $773(18)$ \\
$a$ & $8.59703(13)$ & $0.108(3)$ & $1.52(16)$ & $118(2)$ & $936(33)$ \\
$b$ & $5.21490(4)$ & $0.0481(12)$ & $0.40(3)$ & $117.1(17)$ & $791(22)$ \\
$c$ & $11.93275(9)$ & $0.0246(16)$ & $0.090(8)$ & $48(2)$ & $431(33)$ \\
\hline
\end{tabular}

The variation in the angle $\beta$ was modelled with the equation $\beta=96.8752(10)+$ $0.126(7) T^{T}-0.231(12) T^{2}+0.084(7) T^{3}-0.0130(15) T^{A}$, where $T=T / 100$.
Grüneisen parameter, $\gamma$, defined in Equ. 1. The results (Figure $8 \mathrm{~b}$ ) show that $\gamma$, which measures the variation of vibrational frequencies with temperature, initially increases to reach a maximum of 2.8 at about $30 \mathrm{~K}$, but thereafter drops back to a value near 2 . The drop-off arises because external vibrational modes are populated below $100 \mathrm{~K}$, and these have a greater sensitivity to temperature than the internal vibrational modes which are excited above $100 \mathrm{~K}$ [61]. Note that in this analysis the bulk modulus is assumed to be constant with temperature.

\section{The effect of pressure on the unit cell dimensions of piperidine}

Piperidine- $\mathrm{d}_{11}$ crystallises at room temperature at a pressure of $0.22 \mathrm{GPa}$. The crystal structure obtained is the 


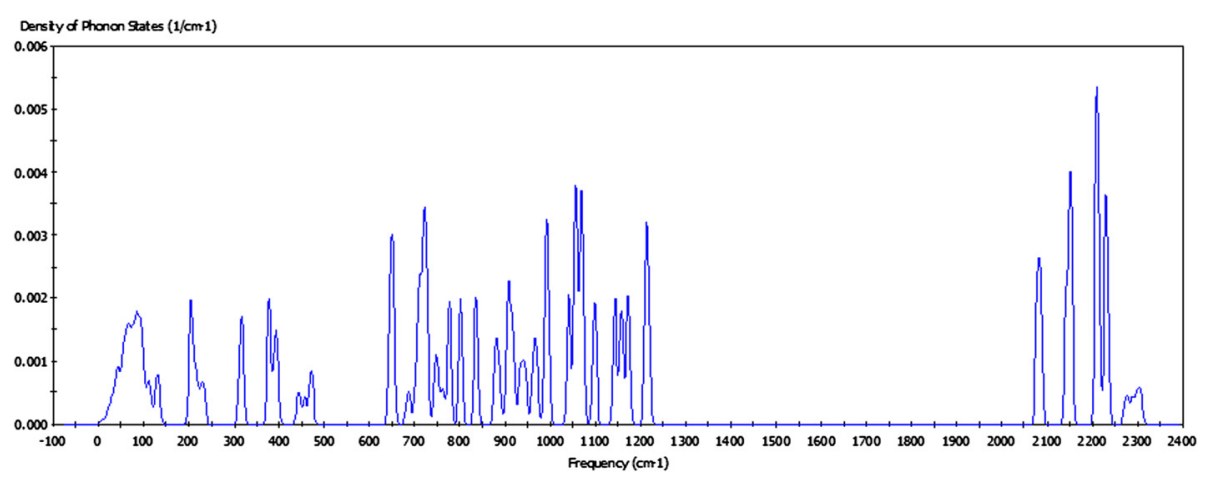

Figure 6 Phonon density of states of piperidine- $d_{11}$ calculated by periodic DFT.

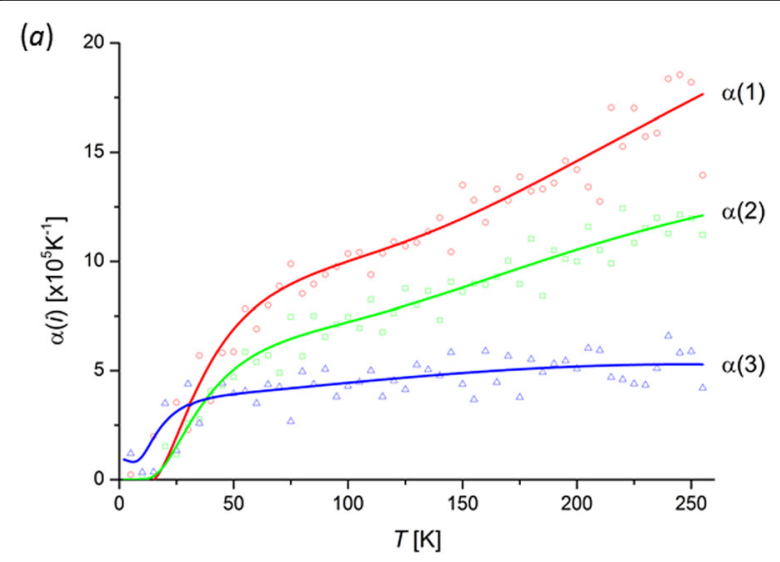

(b)

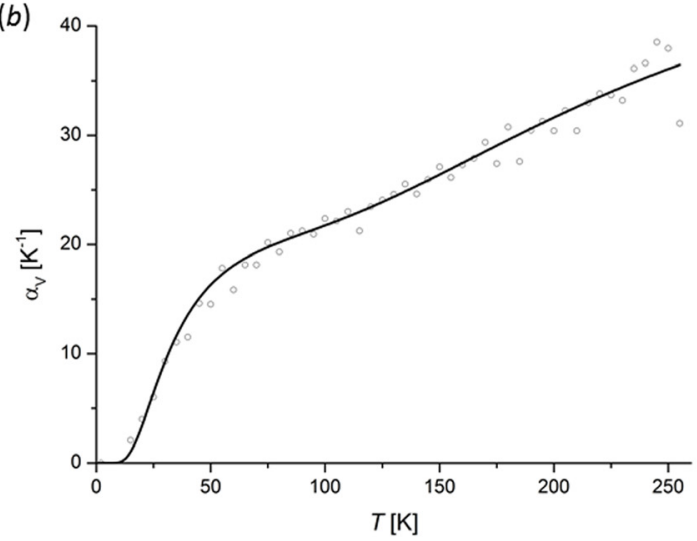

Figure 7 Thermal expansion of piperidine. (a) Principal values of the thermal expansion tensor: $(\boldsymbol{b})$ The volume thermal expansion. In each case the small circles are calculated from pairs of experimental data points, whereas the trend-line is calculated from pairs of points with values taken from the Einstein fits in Figure 5. At very low temperature, the points are calculated from very small differences, and the results less reliable than at higher temperature. same as that described above, with a slightly greater volume than at $2 \mathrm{~K}$. The effect of increasing pressure on the cell parameters and volume is shown in Figure 9a-e, the volume reducing by $15.5 \%$ up to $2.77 \mathrm{GPa}$. The $a$ axis undergoes the greatest reduction in length (6.2\%) between $0.22 \mathrm{GPa}$ and $2.77 \mathrm{GPa}$. The $c$ axis is the least sensitive to pressure, reducing by $4.5 \%$. The principal axes of the strain tensor calculated between 0.22 and 2.77 GPa, shown in Figure 9f., are similar in direction to those determined at ambient pressure between 2.5 and $255 \mathrm{~K}$ (Table 4). The strain is also more isotropic under compression, particularly so at low pressures (Figure $9 f$ and Table 4).

The bulk modulus $(B)$ refined for a third order BirchMurnaghan equation of state [14] is 6.4(4) GPa, though the data-set used to calculate this quantity is admittedly rather limited. The values of $V_{0}$ and $B^{\prime}$ refined to 557.0(15) $\AA^{3}$ and 8.2(8) respectively $\left(\chi^{2}=0.74\right)$. Molecular solids typically have $B<30 \mathrm{GPa}$ and the following $B$ values are useful for comparison [62]: $\mathrm{Ru}_{3}(\mathrm{CO})_{12} 6.6 \mathrm{GPa}, L$-alanine [63] and salicylaldoxime [64] $13.3 \mathrm{GPa}, \mathrm{NaCl} 25 \mathrm{GPa}$, quartz $37 \mathrm{GPa}$, ceramics $50-300 \mathrm{GPa}$ and diamond 440 GPa. Piperidine is thus quite soft compared to other hydrogen bonded materials.

\section{The effect of pressure on the structure of piperidine}

The neutron powder diffraction data obtained at elevated pressure were of medium resolution and modest statistical precision, and during structure refinement the piperidine molecules were treated as rigid bodies with bond distances and angles taken from the X-ray structure at $150 \mathrm{~K}$. To test the validity of the rigid-body assumption, the experimental structures were optimised using periodic DFT, holding the unit cell dimensions fixed to experimental values. Such calculations have been shown to reproduce experimentally determined atomic positions with crystal packing similarity values ${ }^{a}$ of $<0.1 \AA$ [65]. For piperidine, crystal packing similarities $[43,66]$ of the experimental and optimised structures were 

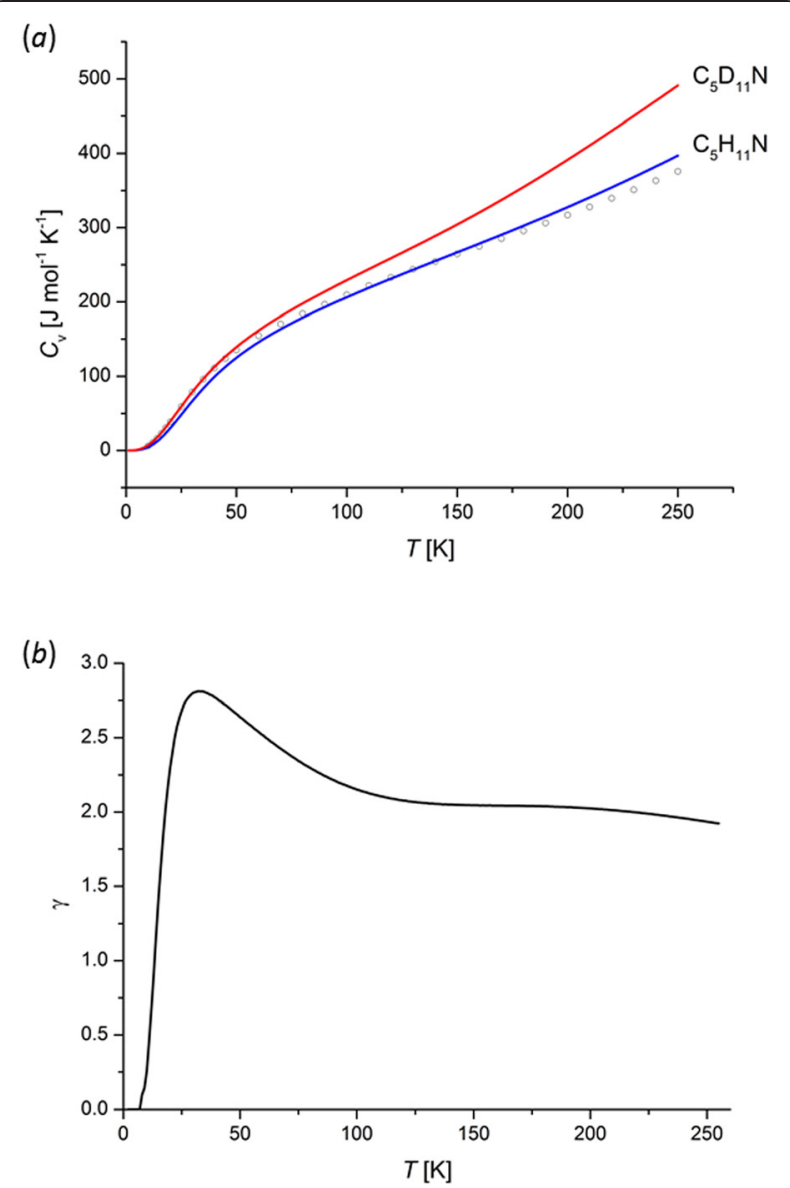

Figure 8 Thermodynamic parameters of crystalline piperidine. (a) The constant-volume heat capacities of piperidine- $h_{11}$ (blue) and piperidine$d_{11}$ (red). The circles are calculated from experimentally-determined $C_{p}$ values measured for the $h_{11}$ isotopologue, and the solid blue line is determined from a DFT phonon calculation. The solid red line was obtained from a similar calculation on the $d_{11}$ system. (b) Variation of the Grüneisen parameter with temperature.

between 0.021 and $0.037 \AA$, confirming that the rigidbody assumption is reasonable.

A movie showing the effect of pressure, generated using optimised structures in the same way as the movie for temperature described above in "The effect of temperature on the structure of piperidine", is available in the Additional file 3: Movie S2a). Comparison of the pressure and temperature series movies shows the more nearly isotropic distribution of strain as well as more prominent changes in the orientations of the molecules under compression. The largest interatomic distance change occurs for $\mathrm{C} 5 \mathrm{H} 10 \ldots \mathrm{H} 3$, which measures $3.04 \AA$ at $0.22 \mathrm{GPa}$ and $2.51 \AA$ at 1.09 GPa, a reduction of $17.4 \%$. Other contacts listed in Table 2 change by between 4 and $8 \%$; the hydrogen bonds shorten from $2.18 \AA$ at $0.22 \mathrm{GPa}$ to $2.09 \AA$ at $1.09 \mathrm{GPa}$. The overall effect is to fill the rather large interstitial voids formed between the H-bonded chains (Figure 10, Additional file 3: Movie S2b).
Over the course of the first one or two kbars of applied pressure, provided the symmetry remains unchanged and volume changes are small, the path of compression might be expected to follow the path of a low-energy lattice vibration. Specifically, the mode would be expected to lie at the $\Gamma$-point and belong to the totally symmetric representation, in the present case, where the lattice point symmetry is $2 / m, A_{1 \mathrm{~g}}$. The lowest totally symmetric phonon, which has a calculated frequency of $36 \mathrm{~cm}^{-1}$ is shown as an animation in the Additional file 4: Movie S3a) and can be compared to a sequential animation of the structures obtained at 0.22 and 0.49 GPa (Additional file 4: Movie S3b). The similarity between the two animations is striking, suggesting that structure determinations at pressures of a few kbar can potentially be used to visualise low-frequency phonons.

\section{Comparison of the effects of pressure and temperature}

The strain induced by cooling or compression is characterised by similarly orientated strain tensors, with largest principal axis lying approximately along a, the middle lying exactly along $\mathbf{b}$ and the smallest approximately along $\mathbf{c}$ (Figure 3c). Though the principal axes are similarly orientated, the tensor describing the response to pressure is more isotropic.

In an attempt to gain some insight into the structural reasons for these similarities and differences the DFToptimised structure at $0.22 \mathrm{GPa}$ was reoptimised with first the $a$ and then the $c$ axis reduced in length by $5 \%$. PIXEL calculations were then carried out on all three optimised structures, referred to as 'opt', 'A', and ' $\mathrm{C}$ ' respectively. The lattice energies were $-55.2,-53.8$ and $-53.1 \mathrm{~kJ} \mathrm{~mol}^{-1}$, respectively; though the differences between these figures are small, they are consistent with the greater compressibility along $\mathbf{a}$. The $\mathrm{H}$-bond energies $\left(\mathrm{kJ} \mathrm{mol}{ }^{-1}\right)$ are $-21.7(\mathrm{opt}),-21.4(\mathrm{~A})$ and $-21.9(\mathrm{C})$, indicating that compression along $\mathbf{c}$ actually stabilises the $\mathrm{H}$-bonds, while compression along a destabilises them. The H-bond distances ( $\AA$ ) are opt 2.136, A 2.074 and C 2.111 , and though in both $\mathrm{A}$ and $\mathrm{C}$ the electrostatic term is more negative as a result of the shorter N...H distance, it is outweighed by a more positive repulsion term in $\mathrm{A}$.

The energies of other contacts are depicted in Figure 11. In all but one case (\#5), the contacts in structure $C$ are less energetic that those in $\mathrm{A}$, indicating that compression along $\mathbf{c}$ destabilises the inter-chain van der Waals interactions more than compression along $\mathbf{a}$. While this explains the greater compressibility along the $a$-direction, it is also clear that the balance is a rather fine one, and this is manifested in the variable pressure series by the more isotropic strain tensor. As pressure increases, the $P V$ contribution to free energy becomes appreciable. As Figure 10 shows, closure of the interstitial voids involves a significant component of $c$-axis shortening, and the isotropy of strain at 
(a)

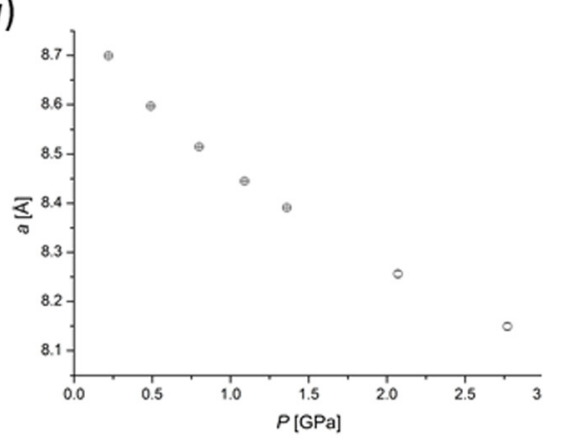

(b)

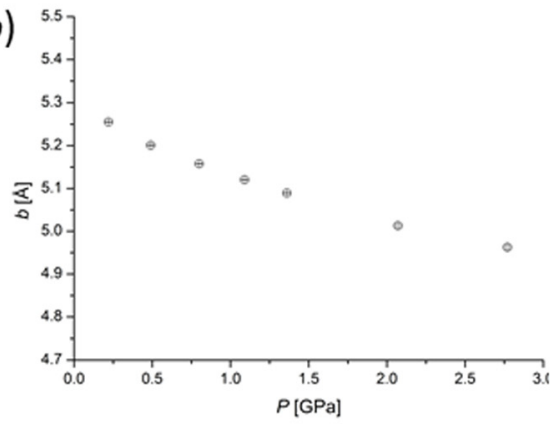

(c)

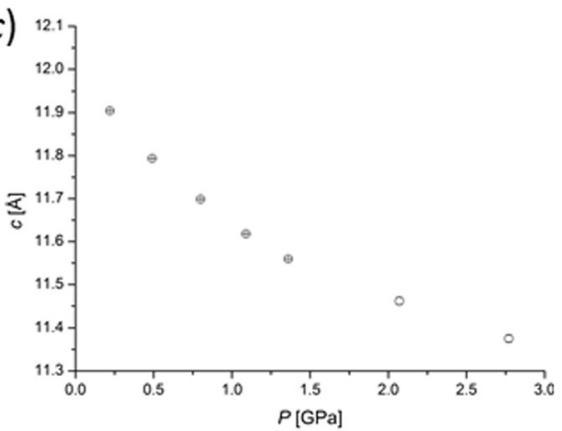

$(d)$

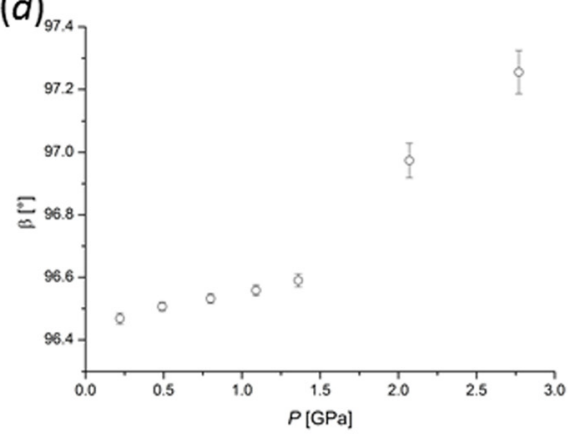

(e)

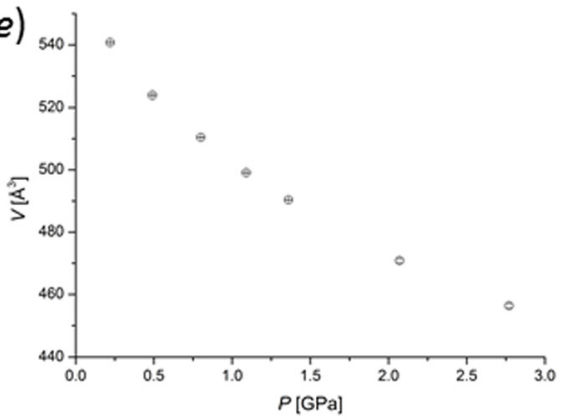

(f)

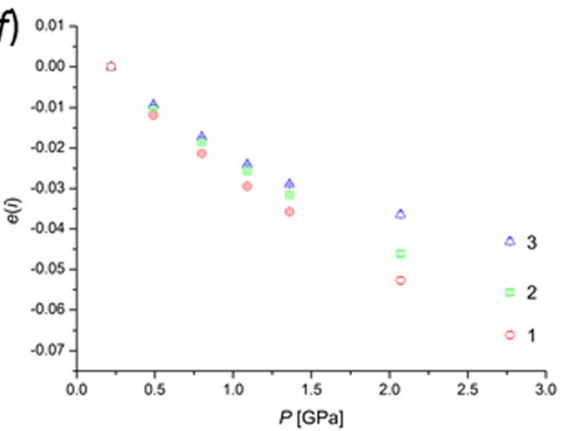

Figure 9 Variation of the lattice parameters with pressure. $(\boldsymbol{a})-(\boldsymbol{d})$ show the trends of the $a, b$ and $c$-axis lengths and the $\beta$-angle with pressure. $(\boldsymbol{e})$ shows the change in volume and $(\boldsymbol{f})$ the principal axes of the strain tensor calculated using the cell dimensions at $0.22 \mathrm{GPa}$ as a reference.

Table 4 Comparison of eigenvalues and eigenvectors of the temperature and pressure induced strain tensors

\begin{tabular}{|c|c|c|c|}
\hline \multicolumn{2}{|c|}{$T(255 \mathrm{~K}$ versus $2 \mathrm{~K})$} & \multicolumn{2}{|c|}{$P(0.22 \mathrm{GPa}$ versus $0.80 \mathrm{GPa})$} \\
\hline Eigenvalue & Eigenvector & Eigenvalue & Eigenvector \\
\hline$-0.026281(14)$ & {$\left[\begin{array}{llll}0.113 & 0.000 & 0.021\end{array}\right]$} & $-0.0213(3)$ & {$\left[\begin{array}{llll}0.115 & 0.000 & 0.016\end{array}\right]$} \\
\hline$-0.019036(10)$ & {$\left[\begin{array}{llll}0.000 & 0.188 & 0.000\end{array}\right]$} & $-0.0186(2)$ & {$\left[\begin{array}{lllll}0.000 & 0.190 & 0.000\end{array}\right]$} \\
\hline$-0.011088(16)$ & {$\left[\begin{array}{llll}-0.016 & 0.000 & 0.081\end{array}\right]$} & $-0.01725(17)$ & {$\left[\begin{array}{llll}-0.009 & 0.000 & 0.083\end{array}\right]$} \\
\hline
\end{tabular}

The volume decrease between 255 and $2 \mathrm{~K}\left(31.2 \AA^{3}\right)$ is similar to that between 0.22 and $0.80 \mathrm{GPa}\left(30.3 \AA^{3}\right)$. Eigenvector components are given with respect to the direct crystallographic axes at $2 \mathrm{~K}$ and $0.22 \mathrm{GPa}$. high pressure is the result of compression along a being favoured by the inter-chain contacts, while compression along $\mathbf{c}$ leads to greater volume reduction.

\section{Conclusions}

We have explored the crystal structure of piperidine under a range of different conditions of temperature and pressure. Although a previous study had indicated another phase exists, no new phases have been identified here, and it is possible that the alternative phase identified by Parkin on the basis of cell dimensions was a metastable form. The crystal structure of piperidine is characterised by chains of molecules linked by $\mathrm{NH} . . . \mathrm{N}$ hydrogen bonds which are disposed about a $2_{1}$ axis running along $\mathbf{b}$. The unit cell of the metastable phase has a 
(a)

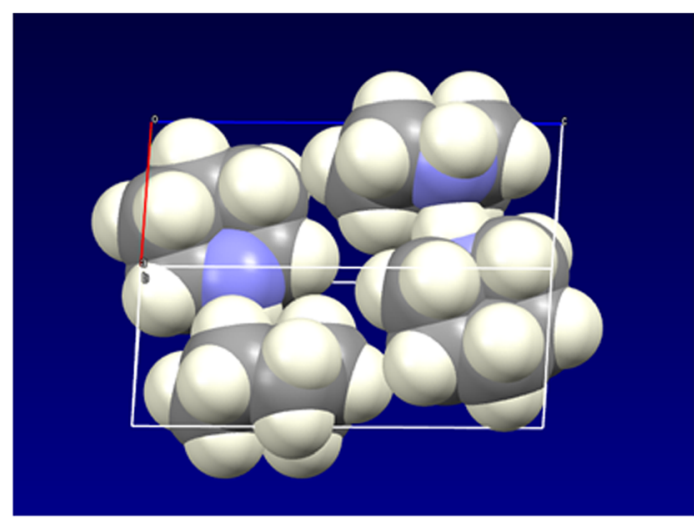

(b)

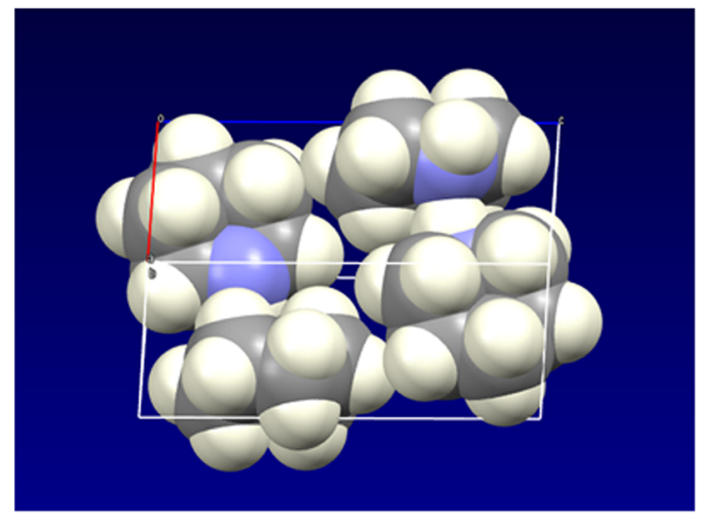

Figure 10 Interstitial voids at (a) 0.22 and (b) 1.09 GPa. Images were generated using the experimentally determined coordinates; a movie extended to 2.77 GPa using the DFT optimised coordinates is available in the Additional file 3: Movie S2b).

$b$ axis length very similar to that of the $b$-axis of the phase discussed in this paper, and both phases are likely to feature similar $\mathrm{H}$-bond chains. Though our original crystal growth experiments and DSC measurements indicated formation of a metastable form, there is no mention of transitions in the report of heat capacity measurements in ref. [52], and it is possible that its formation is dependent on rather specific crystallisation conditions which remain unidentified. Deuteration is also known to influence formation of alternative phases [67].

Though the $\mathrm{H}$-bonds have a characteristic and easily recognisable structural signature, the same is not true of van der Waals interactions [68], but their influence can be appreciated with the aid of packing energy calculations, such as the PIXEL method used here. In the case of piperidine, though $\mathrm{H}$-bonds are the most energetic contacts, around $60 \%$ of the sublimation enthalpy is the result of van der Waals interactions in which individual interatomic distances teeter on the brink of insignificance when assessed in the conventional manner using van der Waals radii.

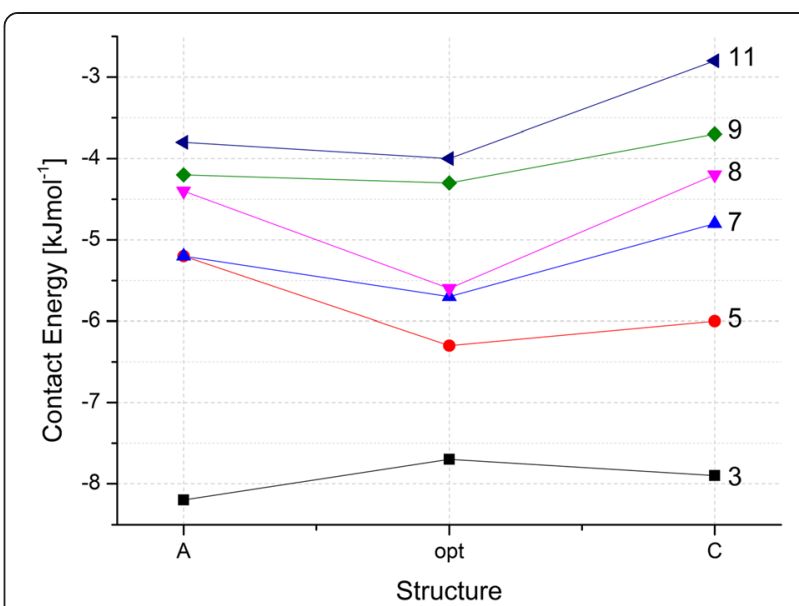

Figure $\mathbf{1 1}$ The effects of a 5\% reduction in the $\boldsymbol{a}$ and $\boldsymbol{c}$ axis lengths on intermolecular contact energies. The energies were calculated for different model structures using the PIXEL method. Model 'opt' refers to the structure at $0.22 \mathrm{GPa}$ after optimisation of the coordinates using DFT (holding the cell dimensions fixed). Model ' $A$ ' was obtained from model 'opt' by reducing the length of the $a$-axis by $5 \%$ and reoptimising the structure. Model ' $C$ ' was obtained in a similar way, but after reducing the length of the c-axis by $5 \%$. The Figures 3 and 5 etc. on the right of the figure refer to the contact numbers listed on the far left of Table 2. Contacts 4, 6, 10 and 12 are symmetry equivalent to those shown. The $\mathrm{H}$-bond contacts 1 and 2 are omitted for clarity.

Periodic DFT calculations reproduce the experimental cell dimensions of piperidine at $2 \mathrm{~K}$ to within $1 \%$. The phonon frequencies calculated using this optimised structure, though they are obtained on the basis of a harmonic model for the energies of small atomic displacements, also reproduce experimental heat capacity data well. These calculations enable the thermal expansion of piperidine to be understood in terms of a simple quantitative model for how energy in the form of heat is absorbed into lattice vibrations.

The response of piperidine to pressure is superficially similar to its response to cooling. Although the principal directions of strain are essentially the same under both sets of varying conditions, the tensor describing the strain developed under pressure is more isotropic. PIXEL calculations demonstrate that the energetic imbalance between the weak van der Waals interactions and the relatively strong $\mathrm{H}$-bonds determines the anisotropy of the strain tensor on cooling. Under pressure the need to fill space efficiently competes with minimisation of free energy though intermolecular contacts, making the strain less anisotropic.

\section{Endnote}

${ }^{\text {a}}$ This is a parameter quantifying the similarity of two crystal structures, and it is defined as the root-mean square deviation calculated for a cluster of 15 molecules taken from each structure. Crystal packing similarities were calculated in MERCURY. 


\section{Additional files}

Additional file 1: Table S1. Unit cell parameters between 2 and $255 \mathrm{~K}$.

Additional file 2: Movie S1. Visualisation of thermal expansion in steps of $25 \mathrm{~K}$. Coordinates were generated by geometry optimisation with periodic DFT holding the cell dimensions fixed at experimentally-determined values.

Additional file 3: Movie S2. Visualisation of the compression series between 0.22 and $2.77 \mathrm{GPa}$. Coordinates generated as in Movie S1 in (a) 'stick' format and (b) space-filling format to show interstitial void space.

Additional file 4: Movie S3. (a) Experimental structures at 0.22 and 0.49 GPa. (b) Animation of the lowest frequency totally symmetric Г-point phonon.

\section{Competing interests}

The authors declare that they have no competing interests.

\section{Authors' contributions}

SP formulated and directed the project. Low-temperature and high-pressure neutron diffraction measurements were respectively performed by RMI and LEB and WGM and LEB. LEB carried-out the structure refinements, and the results interpreted by LEB and SP. Electronic structure calculations was carried out by SP. All authors contributed to the preparation of the manuscript and read and approved the final version.

\section{Acknowledgements}

We thank STFC and ISIS through The Centre for Molecular Structure and Dynamics and EPSRC for studentship funding to LEB. We also thank the ISIS Facility for provision of neutron beam time on the HRPD and PEARL instruments. We also thank the referees for their careful reading of the manuscript.

\section{Author details}

${ }^{1}$ EaStCHEM School of Chemistry and Centre for Science at Extreme Conditions, The University of Edinburgh, King's Buildings, West Mains Road, Edinburgh EH9 3FJ, UK. ${ }^{2}$ ISIS Pulsed Neutron and Muon Facility, STFC Rutherford Appleton Laboratory, Harwell Science and Innovation Campus, Harwell Oxford, Didcot OX11 0QX, UK. ${ }^{3}$ Present address: Neutron Sciences Directorate, Oak Ridge National Laboratory, PO Box 2008 MS6475, Oak Ridge, TN 37831-6457, USA.

\section{Received: 29 October 2014 Accepted: 5 February 2015}

\section{Published online: 12 April 2015}

\section{References}

1. Kahn R, Fourme R, Andre D, Renaud M. Crystal structures of cyclohexane I and II. Acta Crystallogr Sec B: Struct Crystallogr Crystal Chem. 1973;29:131-8.

2. Funnell NP, Dove MT, Goodwin AL, Parsons S, Tucker MG. Local structure correlations in plastic cyclohexane-a reverse Monte Carlo study. J Phys Condens Matter. 2013:25:454204.

3. Parkin A, Oswald IDH, Parsons S. Structures of piperazine, piperidine and morpholine. Acta Crystallogr Sec B-Struct Sci. 2004;60:219-27.

4. Kitigorodski Al. Molecular crystals and molecules. New York: Academic Press; 1973.

5. Ibberson RM. Design and performance of the new supermirror guide on HRPD at ISIS. Nucl Instrum Meth Phys Res Section A: Accelerators Spectrometers Detectors Assoc Equip. 2009;600:47-9.

6. Ibberson RM. A simple technique for preparing low-melting-point samples for neutron powder diffraction. J Appl Crystallogr. 1996;29:498-500.

7. ISIS. Dedicated facility for high pressure diffraction. In: ISIS 96 - ISIS facility annual report 1995-96, Rutherford Appleton laboratory 1996, RAL-TR-96-050. 1996. p. 61-2.

8. ISIS. PEARL - pressure and engineering research line. In: ISIS 97 - ISIS facility annual report 1996-97, Rutherford Appleton laboratory 1997, RAL-TR-97-050. 1997. p. 28-9.

9. Marshall WG, Francis DJ. Attainment of near-hydrostatic compression conditions using the Paris-Edinburgh cell. J Appl Crystallogr. 2002;35:122-5.

10. Besson JM, Nelmes RJ, Halem G, Loveday JS, Weill G, Hull S. Neutron powder diffraction above 10 GPa. Phys B Condens Matter. 1992;180-181:907-10.

11. Besson JM, Nelmes RJ. New developments in neutron-scattering methods under high pressure with the Paris-Edinburgh cells. Phys B Condens Matter. 1995;213\&214:31-6.
12. Le Godec Y, Dove MT, Redfern SAT, Tucker MG, Marshall WG, Syfosse G, et al. Recent developments using the Paris-Edinburgh cell for neutron diffraction at high pressure and high temperature and some applications. High Pressure Res. 2003:23:281-7.

13. Angel RJ. Equations of state. Rev Mineral Geochem. 2002;41:35-59.

14. Birch F. Finite elastic strain of cubic crystals. Phys Rev. 1947;71:809-24.

15. Fortes AD, Wood IG, Alfredsson M, Vocadlo L, Knight KS, Marshall WG, et al. The high-pressure phase diagram of ammonia dihydrate. High Pressure Res. 2007;27:201-12.

16. Fortes AD, Wood IG, Alfredsson M, Vocadlo L, Knight KS, Marshall WG, et al The high-pressure phase diagram of ammonia dihydrate (Corrigendum). High Pressure Res. 2012;32:337-337.

17. Kuznetsov AZ, Dmitriev V, Dubrovinsky L, Prakapenka V, Weber HP. FCC-HCP phase boundary in lead. Solid State Commun. 2002;122:125-7.

18. Miller RA, Schuele DE. Pressure derivatives of the elastic constants of lead. J Phys Chem Solid. 1969;30:589-600

19. Waldorf DL, Alers GA. Low-temperature elastic moduli of lead. J Appl Phys. 1962;33:3266-9.

20. Rietveld HM. Profile refinement method for nuclear and magnetic structures. J Appl Crystallogr. 1969;2:65-71

21. Coelho A. TOPAS-academic: general profile and structure analysis software for powder diffraction data. Version 5. Brisbane, Australia; 2013.

22. Jarvinen M. Application of symmetrized harmonics expansion to correction of the preferred orientation effect. J Appl Crystallogr. 1993;26:525-31.

23. Dunitz JD. X-ray analysis and the structure of organic molecules. Basel, Switzerland: $\mathrm{VCH} ; 1995$

24. Schomaker V, Trueblood KN. Rigid-body motion of molecules in crystals. Acta Crystallogr Section B: Struct Crystallogr Crystal Chem. 1968:24:63-76.

25. Pawley GS. Unit-cell refinement from powder diffraction scans. J Appl Crystallogr. 1981;14:357-61

26. Clark SJ, Segall MD, Pickard CJ, Hasnip PJ, Probert MJ, Refson K, et al. First principles methods using CASTEP. Z Krist. 2005;220:567-70.

27. Inc A. Materials studio version 7. Cambridge, UK: Materials Studio; 2013.

28. Perdew JP, Burke K, Ernzerhof M. Generalized gradient approximation made simple. Phys Rev Lett. 1996;77:3865-8.

29. Monkhorst HJ, Pack JD. Special points for Brillouin-zone integrations. Phys Rev B. 1976:13:5188-92.

30. Tkatchenko A, Scheffler M. Accurate molecular van der Waals interactions from ground-state electron density and free-atom reference data. Phys Rev Lett. 2009;102:073005.

31. McNellis ER, Meyer J, Reuter K. Azobenzene at coinage metal surfaces: role of dispersive van der Waals interactions. Phys Rev B. 2009;80:205414.

32. Refson K, Tulip PR, Clark SJ. Variational density-functional perturbation theory for dielectrics and lattice dynamics. Phys Rev B. 2006;73:155114.

33. Gonze X, Charlier J-C, Teter MP. Interatomic force constants from first principles: the case of alpha-quartz. Phys Rev B. 1994;50:13035-8.

34. Refson K. MODE_FOLLOW. A routine for generating structures distorted along phonon modes calculated using CASTEP. Chilton, OXON, UK: ISIS Facility, Rutherford-Appleton Laboratory; 2014.

35. Frisch GWT MJ, Schlegel HB, Scuseria GE, Robb MA, Cheeseman JR, Scalmani G, et al. Gaussian 09. Wallingford, USA: Gaussian Inc; 2009.

36. Gavezzotti A. Calculation of intermolecular interaction energies by direct numerical integration over electron densities. I. Electrostatic and polarization energies in molecular crystals. J Phys Chem B. 2002;106:4145-54

37. Gavezzotti A. Calculation of intermolecular interaction energies by direct numerical integration over electron densities. 2. An improved polarization model and the evaluation of dispersion and repulsion energies. J Phys Chem B. 2003;107:2344-53.

38. Gavezzotti A. Calculation of lattice energies of organic crystals: the PIXEL integration method in comparison with more traditional methods. Z Krist. 2005;220:499-510.

39. Gavezzotti A. Quantitative ranking of crystal packing modes by systematic calculations on potential energies and vibrational amplitudes of molecular dimers. J Chem Theory Comput. 2005;1:834-40.

40. Gavezzotti A. Molecular aggregation - structure analysis and molecular simulation of crystals and liquids. 1st ed. New York: Oxford University Press; 2007.

41. Gavezzotti A. OPiX. Milan, Italy; 2003.

42. Sheldrick GM. SHELXTL-XP version 6.01. Göttingen, Germany and Madison, Wisconsin, USA: Bruker AXS, Madison Wisc; 2001. 
43. Macrae CF, Bruno IJ, Chisholm JA, Edgington PR, McCabe P, Pidcock E, et al. Mercury CSD 2.0 - new features for the visualization and investigation of crystal structures. J Appl Cryst. 2008;41:466-70.

44. Crystallmpact. DIAMOND version 3.0, visual crystal structure information system. Bonn, Germany: Crystallmpact; 2004.

45. Parsons S. STRAIN, program for calculation of linear strain tensors. 2003.

46. Ohashi Y, Burnham CW. Clinopyroxene lattice deformations. Roles of chemical substitution and temperature. Am Mineral. 1973;58:843-9.

47. Hazen RM, Finger LW. Comparative crystal chemistry: temperature, pressure, composition and the variation of crystal structure. Chichester, New York, USA: John Wiley and Sons; 1982. p. 81.

48. Press WH, Teukolsky SA, Vetterling WT, Flannery BP. Numerical recipes in Fortran. Secondth ed. Cambridge, England: Cambridge University Press; 1992.

49. Angel RJ, Gonzalez-Platas J, Alvaro M. EosFit7c and a Fortran module (library) for equation of state calculations. Z Krist. 2014;229:405-19.

50. Bruno IJ, Cole JC, Edgington PR, Kessler M, Macrae CF, McCabe P, et al. New software for searching the Cambridge structural database and visualizing crystal structures. Acta Crystallogr Sec B: Struct Sci. 2002;B58:389-97.

51. Gould RO, Taylor P, Thorpe M. PUCKER, a program for conformational analysis of 5-8 membered rings. Edinburgh, UK: University of Edinburgh; 1995.

52. Messerly JF, Todd SS, Finke HL, Good WD, Gammon BE. Condensed-phase heat-capacity studies and derived thermodynamic properties for six cyclic nitrogen compounds. J Chem Thermodyn. 1988;20:209-24.

53. Hossenlopp IA, Archer DG. Enthalpies of vaporization of piperidine and 1,2-dimethylbenzene; gas-phase isobaric heat capacities of piperidine. J Chem Thermodyn. 1988;20:1061-8.

54. Chickos JS, Acree Jr WE. Enthalpies of sublimation of organic and organometallic compounds. 1910-2001. J Phys Chem Ref Data. 2002;31:537-698.

55. Fortes AD, Wood IG, Vocadlo L, Brand HEA, Knight KS. Crystal structures and thermal expansion of $\mathrm{a}-\mathrm{MgSO}_{4}$ and $\beta-\mathrm{MgSO}_{4}$ from 4.2 to $300 \mathrm{~K}$ by neutron powder diffraction. J Appl Crystallogr. 2007;40:761-70.

56. Knight KS. A neutron powder diffraction determination of the thermal expansion tensor of crocoite $\left(\mathrm{PbCrO}_{4}\right)$ between $60 \mathrm{~K}$ and $290 \mathrm{~K}$. Mineral Mag. 1996;60:963-72.

57. Schofield PF, Knight KS, Stretton IC. Thermal expansion of gypsum investigated by neutron powder diffraction. Am Mineral. 1996;81:847-51.

58. Cemič L. Thermodynamics in mineral sciences. Berlin: Springer-Verlag; 2005

59. Wallace DC. Thermodynamics of crystals. Mineola, New York: Dover Publications; 1998

60. Schlenker JL, Gibbs GV, Boisen Jr MB. Thermal expansion coefficients for monoclinic crystals: a phenomenological approach. Am Mineral. 1975;60:828-33.

61. Saunders GA, Yogurtcu YK, Macdonald JE, Pawley GS. The elastic behavior of orthorhombic sulfur under pressure. Proc R Soc London Series: Math Phys Eng Sci. 1986;407:325-42.

62. Slebodnick C, Zhao J, Angel R, Hanson BE, Song Y, Liu Z, et al. High pressure study of $\mathrm{Ru}_{3}(\mathrm{CO})_{12}$ by X-ray diffraction, Raman, and infrared spectroscopy. Inorg Chem. 2004;43:5245-52.

63. Funnell NP, Dawson A, Francis D, Lennie AR, Marshall WG, Moggach SA, et al. The effect of pressure on the crystal structure of L-alanine. CrystEngComm. 2010;12:2573-83.

64. Wood PA, Forgan RS, Henderson D, Parsons S, Pidcock E, Tasker PA, et al. Effect of pressure on the crystal structure of salicylaldoxime-l, and the structure of salicylaldoxime-II at 5.93 GPa. Acta Crystallogr Sec B: Struct Sci. 2006;62:1099-111.

65. Binns J, Healy MR, Parsons S, Morrison CA. Assessing the performance of density functional theory in optimizing molecular crystal structure parameters. Acta Crystallogr B. 2014;70:259-67.

66. Childs SL, Wood PA, Rodriguez-Hornedo N, Reddy LS, Hardcastle KI. Analysis of 50 crystal structures containing carbamazepine using the materials module of mercury CSD. Cryst Growth Des. 2009;9:1869-88.

67. Crawford S, Kirchner MT, Blaser D, Boese R, David WIF, Dawson A, et al. Isotopic polymorphism in pyridine. Angewandte Chem Int Ed. 2009;48:755-7.

68. Gavezzotti A. The "sceptical chymist": intermolecular doubts and paradoxes. CrystEngComm. 2013;15:4027-35.

\section{Publish with ChemistryCentral and every scientist can read your work free of charge \\ "Open access provides opportunities to our colleagues in other parts of the globe, by allowing anyone to view the content free of charge." \\ W. Jeffery Hurst, The Hershey Company. \\ - available free of charge to the entire scientific community \\ - peer reviewed and published immediately upon acceptance \\ - cited in PubMed and archived on PubMed Central \\ - yours - you keep the copyright \\ Submit your manuscript here: \\ http://www.chemistrycentral.com/manuscript/<smiles>c1ccccc1</smiles> \\ Chemistry Central}

